\title{
A Developed Multi-Criteria Decision Making Model to Rank Different Scenarios of Electrical Power Generation in Egypt
}

\author{
Hamed M. Elsayed \\ Central Agency for Public \\ Mobilization and Statistics \\ Cairo, Egypt
}

\author{
Hesham A. Hefny \\ Institute of Statistical \\ Studies and Research \\ Cairo University, Egypt
}

\author{
Hisham F. Aly \\ Atomic Energy \\ Authority, Cairo, \\ Egypt
}

\begin{abstract}
Multi-criteria decision support systems are used in various fields of human activities. Every alternative multi-criteria decision making problem can be represented by a set of properties or constraints. The properties may be qualitative \& quantitative. There are different unit, as well as there are different optimization techniques to measure these properties. In this paper a developed fuzzy ANP model is proposed. This model helps decision makers to rank different scenarios of electrical power generation in Egypt. After that a comparison is made between the proposed model and the other ANP techniques.
\end{abstract}

\section{Keywords}

Fuzzy; Analytic network process; Gaussian function; Decisionmaking.

\section{INTRODUCTION}

The analytic network process (ANP) is used to handle multiattribute decision-making problems in real situations when there are interrelationships among decision criteria or alternatives. In the traditional formulation of the ANP, human's judgments are represented as crisp numbers. As some of the evaluation criteria are subjective and qualitative in nature, it is very difficult for the decision-maker to express the preferences using crisp numerical values and to provide exact pair-wise comparison judgments. However, in many real cases the human preference model is uncertain and decision makers may be unable to assign exact numerical values to the comparison judgments. It is more suitable for him to use interval or fuzzy evaluations [1]. This paper discusses a fuzzy ANP approach using Gaussian fuzzy numbers to improve the ANP method. It uses the extent analysis method to represent decision makers' comparison judgments and to decide the final priority of different decision criteria. The proposed model uses the linguistic variables and Gaussian fuzzy numbers as a pair-wise comparison scale for obtaining the priorities of different selection attributes and sub-attributes. The internal relationships among factors are taken into consideration. Finally, the priority weights for main attributes, sub-attributes and alternatives are combined to determine the priority weights of the alternatives. The best alternative is the one with the highest priority weight. These kinds of systems often require highly experienced decision makers to consider vague and uncertain information.

Fuzzy rule-based systems are widely used in a various engineering areas such as data mining, pattern recognition, and process control [2]. Fuzzy logic is a key tool to express knowledge of field experts so that valuable experience of human beings can be inserted into controllers design and applied to handle real-life situations that the classical control approach finds difficult or impossible to tackle [3]. Fuzzy set theory offers a possible means of managing these kinds of data or information. On the other hand, ANP offers a means for dealing with different preferences made to different decision alternatives. This paper aims to propose a fuzzy ANP decisionmaking support system that helps decision-makers for selecting the best alternatives among several offers. It makes also a comparison between the proposed model and other classical ANP methods and evaluates them.

The remainder of the paper is organized as follows: In section 2 , an overview is given for the different methods of electrical power generation. In section 3, Analytic network process (ANP) is explained. FANP based approach is discussed in section 4. Gaussian fuzzy ANP (GFANP) proposed model is developed and the steps of each stage are explained in section 5 . In section 6, results are discussed, and the paper ends with concluding remarks in section 7 .

\section{ELECTRICAL POWER GENERATION}

Electricity generation means generating electric energy from other types of energy. The British scientist Michael Faraday discovered the fundamental principles of electricity generation during the 1820s and early 1830 and his basic method is still used up till now. Electricity can be generated by moving a loop of wire or disc of copper between the poles of a magnet [4]. There are advantages and disadvantages for each system of the electricity generation. The environmental problems and the economic objective play an important role in the operation of power systems [5]. The cost of electricity generated by different sources includes the initial capital, discount rate, the costs of continuous operation, fuel, and maintenance. This type of calculation helps policy makers and others to take proper decisions [6].

\subsection{Thermal Power Stations}

A thermal power station is a power plant in which the steam is the prime mover of turbines. It contains all of the equipment and systems required to produce electricity by using a steam generating from boiling water to drive an electrical generator [7]. The heated water, turns into steam and runs a steam turbine which drives an electrical generator. After passing through the turbine, the steam is condensed in a condenser and recycled to be heated again. This process is known as a Rankine cycle. The design of thermal power stations differs according to the different fuel sources [8].

\subsubsection{Fossil-Fuel Power Stations}

Most electricity today is generated by burning fossil fuels to produce steam. This steam is used to drive a steam turbine that, in turn, generates electricity. These systems allow electricity to be generated where it is needed, since fossil fuels can be transported easily [9]. There is a large world's supply of fossil fuels, but it is finite. Scientists have a lot of calculations to estimate when exactly it will be exhausted. Up till now new 
sources of fossil fuels are being discovered. The rate of discovery is slowing and the difficulty of extraction is increasing in the same time [10].

\subsubsection{Nuclear Power Stations}

Fossil fuels are not used in nuclear power plants so they do not directly emit carbon dioxide. The undesirable increase of the water temperature may have adverse effect on aquatic life [11]. Emission of radioactivity from a nuclear plant must be controlled. Abnormal operation may cause a release of radioactive material on scales ranging from minor to severe. These scenarios are very rare [12].

\subsection{Hydroelectric Power Stations}

Electricity generated by hydropower is called hydroelectricity. In this method the production of electrical power is the result of transferring the potential energy of the gravitational force of falling or flowing water into kinetic energy. About 16 percent of global electricity consumption is come from hydroelectricity. The world's production of hydropower in 2010 is 3,427 terawatt-hours of electricity. There is a rapid rate of increase experienced between 2003 and 2009 [13]. Hydropower is produced in 150 countries around the world. The Asia-Pacific region generates 32 percent of global hydropower in 2010. China produced 721 terawatt-hours in 2010, representing around 17 percent of domestic electricity used and is considered the largest hydroelectricity producer in the world. The Three Gorges Dam in China, Itaipu Dam in Brazil, and Guri Dam in Venezuela are now the three hydroelectricity plants larger than $10 \mathrm{GW}$ in the world [14].

\subsection{Wind Power Stations}

The conversion of wind energy into a useful form of energy is called wind power such as using wind turbines to make electricity. Wind power takes advantage of mechanical energy from the constant flow of air over the surface of the earth. A large wind farm consists of several hundred individual wind turbines. They are connected to the electric power transmission network to transfer electricity to various locations. Offshore wind farms can utilize more frequent and powerful winds than are available to land-based installations. They have less visual impact on the landscape but construction costs are higher. Small onshore wind facilities are used to provide electricity to isolated locations [15].

\subsection{Solar Power Stations a}

Humans have utilized solar energy, radiant light and heat from the sun since ancient times using a range of ever-modern technologies. Solar heating, solar photovoltaic, solar thermal electricity and solar architecture are different forms of solar energy technologies. They can make considerable aids to solve some of the most urgent problems the world now faces [16]. The way solar technologies capture, convert and distribute solar energy, characterizes them into two forms passive solar or active solar. The use of photovoltaic panels and solar thermal collectors to harness the energy are called active solar techniques. Orienting a building to the sun, selecting materials with favorable thermal mass or light dispersing properties, and designing spaces that naturally circulate air are called passive solar techniques [17].

\subsection{Electrical Power Generation in Egypt}

Egypt had installed generating capacity of 20 gigawatts (GW) as of 2010 , with plans to add $25 \mathrm{GW}$ of additional generating capacity by 2020. Around 90 percent of Egypt's electric generating capacity is thermal (natural gas), with the remaining 10 percent hydroelectric, mostly from the Aswan High Dam. All oil-fired plants have been converted to run on natural gas as their primary fuel. Egypt is also planning to build a part-solar power plant at Kureimat, which will have a total planned capacity of $150 \mathrm{MW}$. A Netherlands-funded project is building $60 \mathrm{MW}$ of wind power units in the Suez Canal area. Egypt also has a 22-MW nuclear research reactor at Inshas in the Nile Delta, built by INVAP S.A. of Argentina, which began operation in 1997 [18].

\section{ANALYTIC NETWORK PROCESS (ANP) METHOD}

ANP is the generalized form of AHP method. While the AHP represents a problem with a uni-directional hierarchical relationship, the ANP allows for complex interrelationships among decision levels [19]. ANP is a multi-attribute, decisionmaking approach based on the logic, knowledge, and experience of the experts in the domain. ANP can act as a valuable help for decision making involving both tangible as well as intangible attributes that come with the model under study. ANP depends on the process of extracting managerial inputs, thus allowing for a structured communication among decision makers. Thus, it can be used as a qualitative tool for strategic decision-making problems [20]. The possible dependency among factors can only be determined by internal and external environmental analyses. The structural difference between a hierarchy and a network is shown in Fig. 1.


Fig. 1 Structural difference between a hierarchy and a network:

(a) a hierarchy; (b) a network. 


\section{FUZZY ANP}

The inability of ANP to deal with the uncertainty in the pair wise comparison process has been improved in fuzzy ANP. Instead of a exact value, fuzzy ANP applies a range of values to incorporate the decision maker's impression. Liu et al. developed an advanced quality function deployment model using fuzzy ANP [21]. Quality function deployment (QFD) is a customer-oriented design tool used to ensure that the voice of customers is employed throughout the product planning and design stages. Luo et al. developed a TFN-ANP based approach to evaluate virtual research center with comprehensive performance [22]. The performance evaluation of Virtual Research Center (VRC) is an intrinsically complex multi-dimensional process and it should be evaluated and compared in a multi-criteria analysis method. Sevkli et al. developed a fuzzy ANP based SWOT analysis for the airline industry in Turkey [23]. Strengths, Weaknesses, Opportunities, and Threats (SWOT) analysis have been widely used to evaluate alternative strategies in order to determine the best one for given business setting. Hsu et al. developed a hybrid ANP evaluation model for electronic service quality [24]. This study aims to propose a hybrid analytic network process (ANP) model as an improved method to evaluate multiple-criteria and sub-criteria of e-SQ with the interdependence perspective.

\section{THE PROPOSED MODEL (GFANP)}

\subsection{Problem Formulation}

It is required to develop a decision-making system that helps decision-makers to rank the different scenarios of electrical power generation in Egypt. The highest priority would be the best (see fig. 2). There are 3 alternative scenarios:

Alt\#1: the current one, $90 \%$ thermal power stations and 10\% hydro power mainly from the High Dam.

Alt\#2: $20 \%$ nuclear, $75 \%$ petrol, $5 \%$ other, and

Alt\#3: $25 \%$ nuclear, $65 \%$ petrol, $5 \%$ solar, $5 \%$ other.

\subsection{The Proposed Model}

The proposed model defeats the problem of triangular fuzzy numbers by replacing them with Gaussian fuzzy numbers. It is clear that having Gaussian fuzzy numbers over the preference scale causes real intersection between any number and all the other numbers. This eliminates the problem of getting some alternatives having zeros values in the weight vector and consequently be treated equivalently. Therefore, an altered preference table is proposed, shown in table 1, in which Gaussian fuzzy numbers are introduced. It is shown that the centers ( $\mu$ 's) of the Gaussian preference values must be the same as the crisp preference scale values but the widths ( $\sigma$ 's) can be freely assumed according to the amount of uncertainty.
Table 1: The preference table: $\boldsymbol{\mu}=$ crisp number, $\sigma=0.25$

\begin{tabular}{|c|c|c|c|}
\hline $\begin{array}{l}\text { LINGUISTIC } \\
\text { VARIABLE }\end{array}$ & $\begin{array}{c}\text { Crisp } \\
\text { No. }\end{array}$ & $\begin{array}{c}\text { Triang(x, a, } \\
\text { b, c) }\end{array}$ & $\begin{array}{c}\text { Gaussian(x, } \\
\mu, \sigma)\end{array}$ \\
\hline $\begin{array}{l}\text { Equally } \\
\text { preferred (EP) }\end{array}$ & 1 & $\begin{array}{c}\text { Triang(x,1,1, } \\
\text { 1) }\end{array}$ & $\begin{array}{c}\text { Gaussian(x, } 1 \text {, } \\
0.25)\end{array}$ \\
\hline $\begin{array}{l}\text { Equally to } \\
\text { Weakly } \\
\text { preferred } \\
\text { (EWP) }\end{array}$ & 2 & $\begin{array}{c}\text { Triang }(\mathrm{x}, 1.7 \\
5,2,2.25)\end{array}$ & $\begin{array}{c}\text { Gaussian(x, } 2, \\
0.25)\end{array}$ \\
\hline $\begin{array}{l}\text { Weakly } \\
\text { preferred (WP) }\end{array}$ & 3 & $\begin{array}{c}\text { Triang(x, } \\
2.75,3 \text {, } \\
3.25) \\
\end{array}$ & $\begin{array}{c}\text { Gaussian(x, } 3 \text {, } \\
0.25)\end{array}$ \\
\hline $\begin{array}{l}\text { Weakly to } \\
\text { Moderately } \\
\text { preferred } \\
(\text { WMP) }\end{array}$ & 4 & $\begin{array}{c}\text { Triang(x, } \\
3.75,4 \text {, } \\
4.25)\end{array}$ & $\begin{array}{c}\text { Gaussian(x, } 4, \\
0.25)\end{array}$ \\
\hline $\begin{array}{l}\text { Moderately } \\
\text { preferred (MP) }\end{array}$ & 5 & $\begin{array}{c}\text { Triang }(\mathrm{x}, \\
4.75,5 \\
5.25)\end{array}$ & $\begin{array}{c}\text { Gaussian(x, } 5 \text {, } \\
0.25)\end{array}$ \\
\hline $\begin{array}{l}\text { Moderately to } \\
\text { strongly } \\
\text { preferred } \\
\text { (MSP) }\end{array}$ & 6 & $\begin{array}{c}\text { Triang(x, } \\
5.75,6 \text {, } \\
6.25)\end{array}$ & $\begin{array}{c}\text { Gaussian(x, } 6 \text {, } \\
0.25)\end{array}$ \\
\hline $\begin{array}{l}\text { Strongly } \\
\text { preferred (SP) }\end{array}$ & 7 & $\begin{array}{c}\text { Triang(x, } \\
6.75,7, \\
7.25) \\
\end{array}$ & $\begin{array}{c}\text { Gaussian(x, } 7, \\
0.25)\end{array}$ \\
\hline $\begin{array}{l}\text { Strongly to } \\
\text { very strongly } \\
\text { preferred } \\
\text { (SVP) }\end{array}$ & 8 & $\begin{array}{c}\text { Triang(x, } \\
7.75,8, \\
8.25)\end{array}$ & $\begin{array}{c}\text { Gaussian(x, } 8, \\
0.25)\end{array}$ \\
\hline $\begin{array}{l}\text { Very strongly } \\
\text { preferred (VP) }\end{array}$ & 9 & $\begin{array}{c}\text { Triang }(\mathrm{x}, \\
8.75,9 \\
9.25)\end{array}$ & $\begin{array}{c}\text { Gaussian(x, } 9, \\
0.25)\end{array}$ \\
\hline $\begin{array}{l}\text { Very strongly } \\
\text { to extremely } \\
\text { preferred } \\
\text { (VEP) }\end{array}$ & 10 & Triang(x, 9.75 & $\begin{array}{l}\text { Gaussian(x, } \\
10,0.25)\end{array}$ \\
\hline $\begin{array}{l}\text { Extremely } \\
\text { preferred (XP) }\end{array}$ & 11 & $\begin{array}{l}\text { Triang }(\mathrm{x}, \\
10.75,11, \\
11.25)\end{array}$ & $\begin{array}{c}\text { Gaussian(x, } \\
11,0.25)\end{array}$ \\
\hline
\end{tabular}

Gaussian function is fully determined using only two parameters, i.e. center $(\mu)$ and width $(\sigma)$ and it never has a value equals to zero. Therefore, there is an intersection between every fuzzy number and all the others. In this case, disadvantages of the triangular fuzzy numbers can be eliminated.

We can define Gaussian function as follows:

$\operatorname{Gaussian}(x: \mu, \sigma)=\exp \left[\frac{-(\mathrm{x}-\mu)^{2}}{\sigma^{2}}\right]$ 


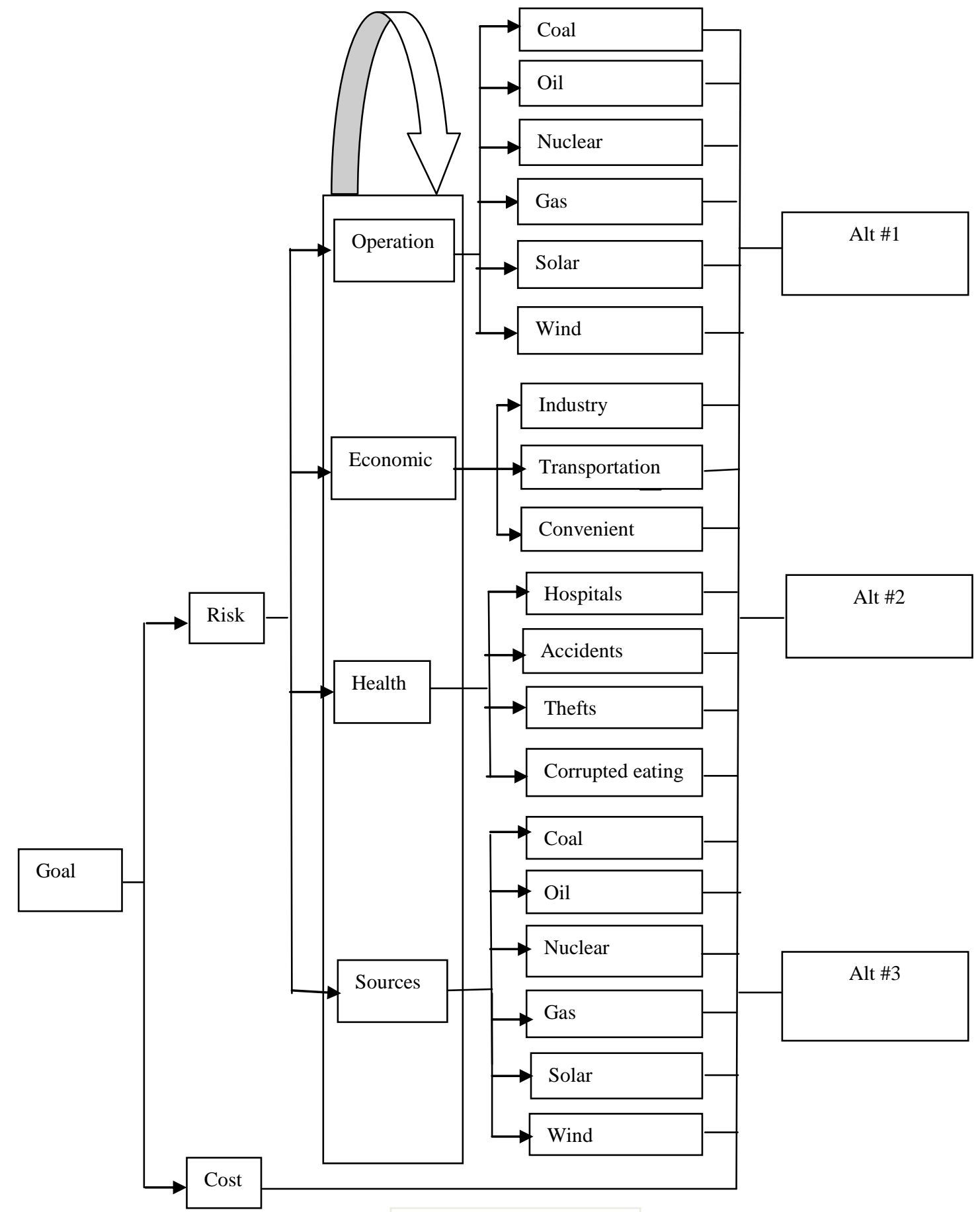

Fig. 2 The ANP Model

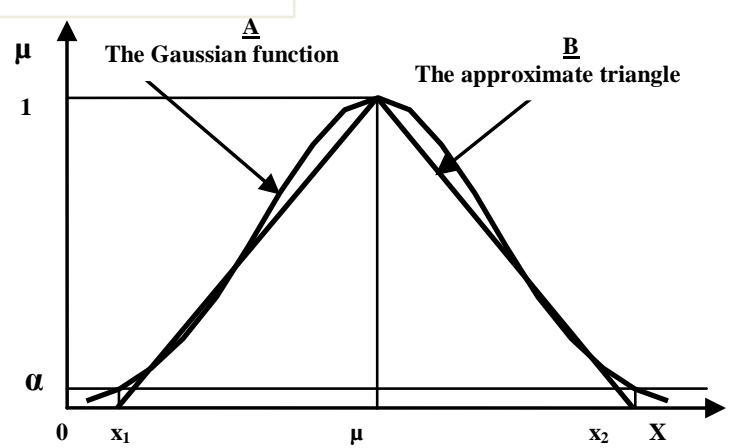

Fig. 3 Gaussian Function $\underline{\mathbf{A}}$ and its approximated triangle $\underline{B}$ 
At any level $\alpha$ cut, as in Fig. 3, it is shown that:

$$
\begin{aligned}
& \alpha=\exp \left[\frac{-(\mathrm{x}-\mu)^{2}}{\sigma^{2}}\right] \\
& \therefore x_{1}=\mu-\sigma \times \sqrt{-\operatorname{Ln}(\alpha)} \text { and } \\
& x_{2}=\mu+\sigma \times \sqrt{-\operatorname{Ln}(\alpha)}
\end{aligned}
$$

A good fuzzy triangular approximation of $\mathrm{G}(\mathrm{x}, \mu, \sigma)$ can be gotten by $\mathrm{T}\left(\mathrm{x}, \mathrm{x}_{1}, \mu, \mathrm{x}_{2}\right)$. This approximation is useful for implementing the fuzzy arithmetic operations to get $S_{i}$ as shown in equation (5). When $S_{i}$ 's can be gotten as triangle fuzzy numbers, they can be returned back to Gaussian to perform the ranking step.

For example suppose that

$\sigma=0.25$ and $\alpha=0.1$ then

$x_{1}=\mu-0.58$ and

$x_{2}=\mu+0.58$

The steps of the developed fuzzy ANP (FANP) method are explained as follows:

Let $\mathrm{G}_{\mathrm{ij}}$ be the elements of the preference matrix after implementing the triangular approximation, then:

\section{Step 1:}

$$
\begin{gathered}
S_{i}=\frac{\sum_{\mathrm{j}} \mathrm{G}_{\mathrm{ij}}}{\sum_{\mathrm{i}} \sum_{\mathrm{j}} \mathrm{G}_{\mathrm{ij}}} \\
=\frac{\sum_{\mathrm{j}}\left(\mathrm{l}_{\mathrm{i}}^{\mathrm{j}}, \mathrm{m}_{\mathrm{i}}^{\mathrm{j}}, \mathrm{u}_{\mathrm{i}}^{\mathrm{j}}\right)}{\sum_{\mathrm{i}} \sum_{\mathrm{j}}\left(\mathrm{l}_{\mathrm{i}}^{\mathrm{j}}, \mathrm{m}_{\mathrm{i}}^{\mathrm{j}}, \mathrm{u}_{\mathrm{i}}^{\mathrm{j}}\right)}
\end{gathered}
$$

Where

$$
\begin{aligned}
& 1_{\mathrm{i}}^{\mathrm{j}} \cong \mathrm{m}_{\mathrm{i}}^{\mathrm{j}}-\sigma_{\mathrm{i}}^{\mathrm{j}} \sqrt{-\operatorname{Ln}(\alpha)} \\
& \mathrm{u}_{\mathrm{i}}^{\mathrm{j}} \cong \mathrm{m}_{\mathrm{i}}^{\mathrm{j}}+\sigma_{\mathrm{i}}^{\mathrm{j}} \sqrt{-\operatorname{Ln}(\alpha)}
\end{aligned}
$$

To get a better triangular approximation, we have to choose a low level for $\alpha$.

For example let $\alpha=0.001$

$$
\begin{array}{r}
\therefore S_{i}=\frac{\left(\sum_{j} 1_{i}^{j}, \sum_{j} m_{i}^{j}, \sum_{j} u_{i}^{j}\right)}{\left(\sum_{i} \sum_{j} 1_{i}^{j}, \sum_{i} \sum_{j} m_{i}^{j}, \sum_{i} \sum_{j} u_{i}^{j}\right)} \\
=\left(\frac{\sum_{j} 1_{i}^{j}}{\sum_{i} \sum_{j} u_{i}^{j}}, \frac{\sum_{j} m_{i}^{j}}{\sum_{i} \sum_{j} m_{i}^{j}}, \frac{\sum_{j} u_{i}^{j}}{\sum_{i} \sum_{i}^{j}}\right) \\
\sum_{j} 1_{i}^{j}=\sum_{j} m_{i}^{j}-\sum_{j} \sigma_{i}^{j}(\sqrt{-\operatorname{Ln}(\alpha)}) \\
\sum_{j} u_{i}^{j}=\sum_{j} m_{i}^{j}+\sum_{j} \sigma_{i}^{j}(\sqrt{-\operatorname{Ln}(\alpha)})
\end{array}
$$

$$
\begin{aligned}
& \sum_{\mathrm{i}} \sum_{\mathrm{j}} 1_{\mathrm{i}}^{\mathrm{j}}=\sum_{\mathrm{i}} \sum_{\mathrm{j}} \mathrm{m}_{\mathrm{i}}^{\mathrm{j}}-\sum_{\mathrm{i}} \sum_{\mathrm{j}} \sigma_{\mathrm{i}}^{\mathrm{j}}(\sqrt{-\operatorname{Ln}(\alpha)}) \\
& \sum_{\mathrm{i}} \sum_{\mathrm{j}} \mathrm{u}_{\mathrm{i}}^{\mathrm{j}}=\sum_{\mathrm{i}} \sum_{\mathrm{j}} \mathrm{m}_{\mathrm{i}}^{\mathrm{j}}+\sum_{\mathrm{i}} \sum_{\mathrm{j}} \sigma_{\mathrm{i}}^{\mathrm{j}}(\sqrt{-\operatorname{Ln}(\alpha)}) \\
& \therefore \mathrm{S}_{\mathrm{i}}=\left(\mathrm{x}_{\mathrm{s}_{\mathrm{i}}}^{\mathrm{L}}, \mathrm{m}_{\mathrm{s}_{\mathrm{i}}}, \mathrm{x}_{\mathrm{s}_{\mathrm{i}}}^{\mathrm{R}}\right)
\end{aligned}
$$

Where

$$
\begin{aligned}
& \mathrm{m}_{\mathrm{s}_{\mathrm{i}}}=\frac{\sum_{\mathrm{j}} \mathrm{m}_{\mathrm{i}}^{\mathrm{j}}}{\sum_{\mathrm{i}} \sum_{\mathrm{j}} \mathrm{m}_{\mathrm{i}}^{\mathrm{j}}} \\
& \mathrm{x}_{\mathrm{s}_{\mathrm{i}}}^{\mathrm{L}}=\frac{\sum_{\mathrm{j}} 1_{\mathrm{i}}^{\mathrm{j}}}{\sum_{\mathrm{i}} \sum_{\mathrm{j}} \mathrm{u}_{\mathrm{i}}^{\mathrm{j}}} \\
& \mathrm{x}_{\mathrm{s}_{\mathrm{i}}}^{\mathrm{R}}=\frac{\sum_{\mathrm{j}} \mathrm{u}_{\mathrm{i}}^{\mathrm{j}}}{\sum_{\mathrm{i}} \sum_{\mathrm{j}} 1_{\mathrm{i}}^{\mathrm{j}}}
\end{aligned}
$$

Now, $S_{i}$ can be returned back to an asymmetric Gaussian fuzzy number as follows:

$$
\begin{gathered}
\sigma_{s_{i}}^{L}=\frac{m_{s_{i}}-x_{s_{i}}^{L}}{\sqrt{-\operatorname{Ln}(\alpha)}} \\
\sigma_{s_{i}}^{R}=\frac{x_{s_{i}}^{R}-m_{s_{i}}}{\sqrt{-\operatorname{Ln}(\alpha)}}
\end{gathered}
$$

Where $\sigma_{s_{i}}^{L}$ : is the width of the left side of the Gaussian fuzzy number and

$$
\sigma_{s_{i}}^{R} \text { : is the width of the right side of the Gaussian fuzzy }
$$
number.

Now, $S_{i}$ turns to an asymmetric Gaussian number as follows:

$$
\mu_{s_{i}}(x)=\left\{\begin{array}{ll}
\exp \left[-\left(\frac{x-m_{s_{i}}}{\sigma_{s_{i}}^{L}}\right)^{2}\right] & \text { if } x \leq m_{s_{i}} \\
\exp \left[-\left(\frac{x-m_{s_{i}}}{\sigma_{s_{i}}^{R}}\right)^{2}\right] & \text { if } x>m_{s_{i}}
\end{array}\right\}
$$

Step 2:

Let $\mu_{1}(\mathrm{x})$ and $\mu_{2}(\mathrm{x})$ be two Gaussian fuzzy numbers having the following equations:

$$
\mu_{\mathrm{s}_{1}}(\mathrm{x})=\left\{\begin{array}{ll}
\exp \left[-\left(\frac{\mathrm{x}-\mathrm{m}_{\mathrm{s}_{1}}}{\sigma_{\mathrm{s}_{1}}^{\mathrm{L}}}\right)^{2}\right] & \text { if } \mathrm{x} \leq \mathrm{m}_{\mathrm{s}_{1}} \\
\exp \left[-\left(\frac{\mathrm{x}-\mathrm{m}_{\mathrm{s}_{1}}}{\sigma_{\mathrm{s}_{1}}^{\mathrm{R}}}\right)^{2}\right] & \text { if } \mathrm{x}>\mathrm{m}_{\mathrm{s}_{1}}
\end{array}\right\}
$$


and

$$
\mu_{\mathrm{s}_{2}}(\mathrm{x})=\left\{\begin{array}{ll}
\exp \left[-\left(\frac{\mathrm{x}-\mathrm{m}_{\mathrm{s}_{2}}}{\sigma_{\mathrm{s}_{2}}^{\mathrm{L}}}\right)^{2}\right] & \text { if } \mathrm{x} \leq \mathrm{m}_{\mathrm{s}_{2}} \\
\exp \left[-\left(\frac{\mathrm{x}-\mathrm{m}_{\mathrm{s}_{2}}}{\sigma_{\mathrm{s}_{2}}^{\mathrm{R}}}\right)^{2}\right] & \text { if } \mathrm{x}>\mathrm{m}_{\mathrm{s}_{2}}
\end{array}\right\}
$$

Fig. 4 shows the intersection point between two Gaussian functions.

$$
v=\left\{\begin{array}{ll}
\exp \left[-\left(\frac{\left(\mathrm{m}_{\mathrm{s}_{2}}-\mathrm{m}_{\mathrm{s}_{1}}\right)}{\left(\sigma_{\mathrm{s}_{1}}^{L}+\sigma_{\mathrm{s}_{2}}^{\mathrm{R}}\right)}\right)^{2}\right] & \text { if } \mathrm{m}_{\mathrm{s}_{1}}>\mathrm{m}_{\mathrm{s}_{2}} \\
\exp \left[-\left(\frac{\left(\mathrm{m}_{\mathrm{s}_{2}}-\mathrm{m}_{\mathrm{s}_{1}}\right)}{\left(\sigma_{\mathrm{s}_{1}}^{R}+\sigma_{\mathrm{s}_{2}}^{\mathrm{L}}\right)}\right)^{2}\right] & \text { if } \mathrm{m}_{\mathrm{s}_{1}}<\mathrm{m}_{\mathrm{s}_{2}}
\end{array}\right\}
$$

The degree of possibility of having $S_{2}=\mu_{S_{2}}(x) \geq S_{1}=\mu_{S_{1}}$ (x) can be defined as

$$
\forall\left(S_{2} \geq S_{1}\right)=\operatorname{hgt}\left(S_{1} \cap S_{2}\right)=\mu_{\mathrm{s}_{2}}\left(\mathrm{x}_{\text {int }}\right)
$$

$$
\forall\left(S_{2} \geq S_{1}\right)=\left\{\begin{array}{ll}
1 & \text { if } \mathrm{m}_{\mathrm{s}_{2}} \geq \mathrm{m}_{\mathrm{s}_{1}}, \\
\exp \left[-\left(\frac{\left.\left.\left(\mathrm{m}_{\mathrm{s}_{2}}-\mathrm{m}_{\mathrm{s}_{1}}\right)\right)^{2}\right]}{\left(\sigma_{\mathrm{s}_{2}}^{R}+\sigma_{\mathrm{s}_{1}}^{L}\right)}\right]\right. & \text { if } \mathrm{m}_{\mathrm{s}_{2}}<\mathrm{m}_{\mathrm{s}_{1}}
\end{array}\right\}
$$

where $\left(\mathbf{X}_{\mathbf{i n t}}, \mathbf{v}\right)$ is the inner intersection point between $\mu_{\mathrm{S}_{2}}(\mathrm{x})$ and $\mu_{\mathrm{S}_{1}}(\mathrm{x})$.

Step 3:

The degree of possibility for a Gaussian fuzzy number $\mathrm{S}$ to be greater than $\mathrm{k}$ Gaussian fuzzy numbers $S_{\mathrm{i}}(i=1,2, \ldots, \mathrm{k})$ is defined by

$$
\begin{aligned}
& \forall\left(S>S_{1}, S_{2}, \ldots \ldots . S_{k}\right) \\
= & \forall\left[\left(S>S_{1}\right) \text { and }\left(S>S_{2}\right) \text { and } \ldots \ldots \text {...and }\left(S>S_{k}\right)\right]
\end{aligned}
$$

(26)

$$
=\min \forall\left(S>S_{i}\right), i=1,2,3, \ldots \ldots ., k .
$$

\section{Assume that}

$d^{\prime}\left(A_{i}\right)=\min \forall\left(S_{i}>S_{j}\right)$ for $j=1,2, \ldots, n ; j \neq i$.

Then the weight vector can be given by:

$$
W^{\prime}=\left(d^{\prime}\left(A_{1}\right), d^{\prime}\left(A_{2}\right), \ldots . ., d^{\prime}\left(A_{n}\right)\right)^{T} \text {, }
$$

where $\mathrm{A}_{\mathrm{i}}(\mathrm{i}=1,2, \ldots, \mathrm{n})$ are $\mathrm{n}$ elements.

\section{Step 4:}

Via normalization, the normalized weight vector can be determined as:

$$
\begin{aligned}
& W=\left(d\left(A_{1}\right), d\left(A_{2}\right), \ldots . ., d\left(A_{n}\right)\right)^{T}, \\
& \text { where } \mathrm{d}\left(\mathrm{A}_{\mathrm{i}}\right)=\frac{\mathrm{d}^{\prime}\left(\mathrm{A}_{\mathrm{i}}\right)}{\sum_{\mathrm{i}} \mathrm{d}^{\prime}\left(\mathrm{A}_{\mathrm{i}}\right)}
\end{aligned}
$$

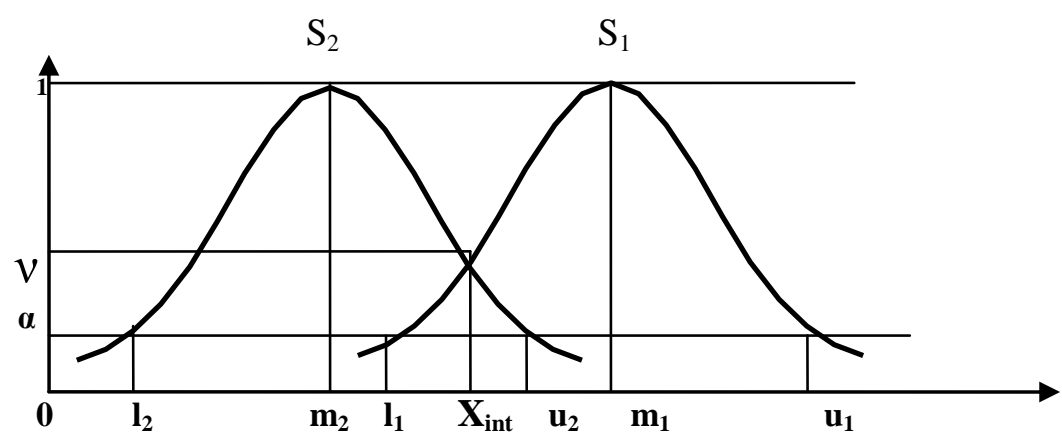

Fig. 4 Intersection Point between Two Gaussian Functions 


\section{EXPERMENTAL RESULTS \\ DISCUSSION}

AND

The linguistic pair-wise comparison matrices of the different criteria nodes are given in tables 2 to 7 . On the other hand, the inner dependency matrices with respect to different criteria nodes are given in tables 8 to 11 . The inner dependency among factors is shown in Fig. 5.

Table 2: The Goal evaluation matrix

\begin{tabular}{|l|l|l|}
\hline Goal & Risk & Cost \\
\hline Risk & EP & WMP \\
\hline Cost & & EP \\
\hline
\end{tabular}

Table 3: The Risk evaluation matrix

\begin{tabular}{|l|l|l|l|l|}
\hline Risk & Operation & Economic & Health & Sources \\
\hline Operation & EP & WMP & EWP & WP \\
\hline Economic & & EP & EWP & EWP \\
\hline Health & & & EP & EP \\
\hline Sources & & & & EP \\
\hline
\end{tabular}

Table 4: The Operation evaluation matrix

\begin{tabular}{|l|l|l|l|l|l|l|}
\hline Operation & Coal & Oil & Nuclear & Gas & Solar & Wind \\
\hline Coal & EP & & & & & \\
\hline Oil & WMP & EP & EP & & & \\
\hline Nuclear & EWP & & EP & & & \\
\hline Gas & WP & EWP & EWP & EP & & \\
\hline Solar & MP & WP & EWP & EWP & EP & \\
\hline Wind & WMP & WP & EWP & EWP & EWP & EP \\
\hline
\end{tabular}

Table 5: The Economic evaluation matrix

\begin{tabular}{|l|l|l|l|}
\hline Economic & Industry & Transportation & Convenient \\
\hline Industry & EP & EP & EP \\
\hline Transportation & & EP & EP \\
\hline Convenient & & & EP \\
\hline
\end{tabular}

Table 6: The Health evaluation matrix

\begin{tabular}{|l|l|l|l|l|}
\hline Health & Hospitals & Accidents & Thefts & Corr. Eating \\
\hline Hospitals & EP & WP & EWP & EWP \\
\hline Accidents & & EP & WP & EWP \\
\hline Thefts & & & EP & EP \\
\hline $\begin{array}{l}\text { Corr. } \\
\text { Eating }\end{array}$ & & & & EP \\
\hline
\end{tabular}

Table 7: The Sources evaluation matrix

\begin{tabular}{|l|l|l|l|l|l|l|}
\hline Sources & Coal & Oil & Nuclear & Gas & Solar & Wind \\
\hline Coal & EP & & & & & \\
\hline Oil & EWP & EP & & & & \\
\hline Nuclear & WP & EWP & EP & & & \\
\hline Gas & WP & EWP & EWP & EP & & \\
\hline Solar & MP & WMP & WP & EWP & EP & EP \\
\hline Wind & MP & WMP & WP & EWP & & EP \\
\hline
\end{tabular}

$$
w_{1}=\left[\begin{array}{c}
\text { Operation } \\
\text { Economic } \\
\text { Health } \\
\text { Sources }
\end{array}\right]=\left[\begin{array}{l}
0.30 \\
0.27 \\
0.23 \\
0.20
\end{array}\right]
$$

\section{$\underline{\text { Inner relationship }}$}

Table 8: The inner dependence matrix with respect to the Operation

\begin{tabular}{|l|l|l|l|}
\hline Operation & Economic & Health & Sources \\
\hline Economic & EP & EP & \\
\hline Health & & EP & \\
\hline Sources & EWP & EWP & EP \\
\hline
\end{tabular}

Table 9: The inner dependence matrix with respect to the Economic

\begin{tabular}{|l|l|l|l|}
\hline Economic & Operation & Health & Sources \\
\hline Operation & EP & & EWP \\
\hline Health & EWP & EP & EWP \\
\hline Sources & & & EP \\
\hline
\end{tabular}

Table 10: The inner dependence matrix with respect to the Health

\begin{tabular}{|l|l|l|l|}
\hline Health & Operation & Economic & Sources \\
\hline Operation & EP & & EWP \\
\hline Economic & EWP & EP & EWP \\
\hline Sources & & & EP \\
\hline
\end{tabular}

Table 11: The inner dependence matrix with respect to the Sources

\begin{tabular}{|l|l|l|l|}
\hline Sources & Operation & Economic & Health \\
\hline Operation & EP & & EWP \\
\hline Economic & EWP & EP & EWP \\
\hline Health & & & EP \\
\hline
\end{tabular}

$W_{2}=\left[\begin{array}{llll}1.00 & 0.33 & 0.33 & 0.33 \\ 0.25 & 1.00 & 0.48 & 0.48 \\ 0.25 & 0.48 & 1.00 & 0.19 \\ 0.50 & 0.19 & 0.19 & 1.00\end{array}\right]$

$\mathrm{V}_{\text {factors }}=\mathrm{W}_{2} * \mathrm{~W}_{1}=\left[\begin{array}{cccc}1.00 & 0.33 & 0.33 & 0.33 \\ 0.25 & 1.00 & 0.48 & 0.48 \\ 0.25 & 0.48 & 1.00 & 0.19 \\ 0.50 & 0.19 & 0.19 & 1.00\end{array}\right]$ * $\left[\begin{array}{l}0.30 \\ 0.27 \\ 0.23 \\ 0.20\end{array}\right]=\left[\begin{array}{l}0.27 \\ 0.28 \\ 0.23 \\ 0.22\end{array}\right]$

Some of the preference matrices of the alternatives over criteria are given in tables from 12 to 18 . 


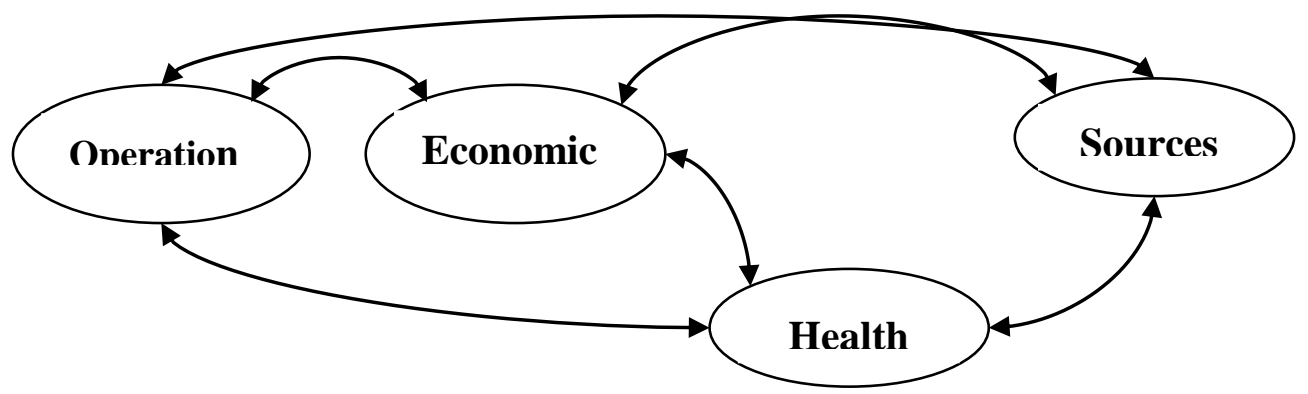

Fig. 5 Inner dependence among factors.

\section{$\underline{\text { Alternatives }}$}

Table 12: The Cost evaluation matrix

\begin{tabular}{|l|l|l|l|}
\hline Cost & Alt. \#1 & Alt. \#2 & Alt. \#3 \\
\hline Alt. \#1 & EP & EWP & WP \\
\hline Alt. \#2 & & EP & \\
\hline Alt. \#3 & & EWP & EP \\
\hline
\end{tabular}

Table 13: The Coal evaluation matrix

\begin{tabular}{|l|l|l|l|}
\hline Coal & Alt. \#1 & Alt. \#2 & Alt. \#3 \\
\hline Alt. \#1 & EP & & \\
\hline Alt. \#2 & EWP & EP & \\
\hline Alt. \#3 & WP & EWP & EP \\
\hline
\end{tabular}

Table 14: The Oil evaluation matrix

\begin{tabular}{|l|l|l|l|}
\hline Oil & Alt. \#1 & Alt. \#2 & Alt. \#3 \\
\hline Alt. \#1 & EP & & \\
\hline Alt. \#2 & EWP & EP & \\
\hline Alt. \#3 & WP & WP & EP \\
\hline
\end{tabular}

Table 15: The Nuclear evaluation matrix

\begin{tabular}{|l|l|l|l|}
\hline Nuclear & Alt. \#1 & Alt. \#2 & Alt. \#3 \\
\hline Alt. \#1 & EP & & \\
\hline Alt. \#2 & EWP & EP & \\
\hline Alt. \#3 & EWP & EWP & EP \\
\hline
\end{tabular}

Table 16: The Gas evaluation matrix

\begin{tabular}{|l|l|l|l|}
\hline Gas & Alt. \#1 & Alt. \#2 & Alt. \#3 \\
\hline Alt. \#1 & EP & & \\
\hline Alt. \#2 & WP & EP & \\
\hline Alt. \#3 & WP & EWP & EP \\
\hline
\end{tabular}

Table 17: The Solar evaluation matrix

\begin{tabular}{|l|l|l|l|}
\hline Solar & Alt. \#1 & Alt. \#2 & Alt. \#3 \\
\hline Alt. \#1 & EP & & \\
\hline Alt. \#2 & WP & EP & \\
\hline Alt. \#3 & EWP & EWP & EP \\
\hline
\end{tabular}

Table 18: The Wind evaluation matrix

\begin{tabular}{|l|l|l|l|}
\hline Wind & Alt. \#1 & Alt. \#2 & Alt. \#3 \\
\hline Alt. \#1 & EP & & \\
\hline Alt. \#2 & WP & EP & \\
\hline Alt. \#3 & WP & WP & EP \\
\hline
\end{tabular}

Finally, the overall normalized priority weight vector of the alternatives can be gotten as follows:

$$
W=[0.25,0.33,0.42]^{T} \text {, }
$$

And this means that Alt.\#3 is the best alternative.
Table 19 gives both the final weights, and ranking for the alternatives according to each proposed method.

Table 19: Final weights and ranking of the alternatives according to each proposed method

\begin{tabular}{||l|l|l|l|l|l|l||}
\hline \hline & \multicolumn{2}{|c|}{ ANP } & \multicolumn{2}{c|}{ Fuzzy ANP } & \multicolumn{2}{c||}{ Proposed Model } \\
\cline { 2 - 7 } & Weight & Rank & Weight & Rank & Weight & Rank \\
\hline Alt\#1 & 0.19 & 3 & 0.0 & 2 & 0.25 & 3 \\
\hline Alt\#2 & 0.32 & 2 & 0.0 & 2 & 0.33 & 2 \\
\hline Alt\#3 & 0.49 & 1 & 1.0 & 1 & 0.42 & 1 \\
\hline \hline
\end{tabular}

As shown in table 20, four different field experts (who set the initial values in preference matrices) were asked to give their opinions to what extent these results are close to the optimum according to their points of views. Also suggested weights for the chosen experts according to their past experiences were put and these weights were approved by them.

Table 20: Evaluation of the proposed methods according to the experts' opinions

\begin{tabular}{|c|c|c|c|c|}
\hline & \multirow[b]{2}{*}{ Experts } & \multirow[b]{2}{*}{ Weight } & \multicolumn{2}{|c|}{ Evaluation of Results } \\
\hline & & & Primary & Final \\
\hline \multirow{4}{*}{ ANP } & Expert I & 0.50 & $85 \%$ & \multirow{4}{*}{$82 \%$} \\
\hline & Expert II & 0.20 & $80 \%$ & \\
\hline & Expert III & 0.20 & $80 \%$ & \\
\hline & Expert IV & 0.10 & $70 \%$ & \\
\hline \multirow{4}{*}{$\begin{array}{l}\text { Fuzzy } \\
\text { ANP }\end{array}$} & Expert I & 0.50 & $70 \%$ & \multirow{4}{*}{$70 \%$} \\
\hline & Expert II & 0.20 & $65 \%$ & \\
\hline & Expert III & 0.20 & $70 \%$ & \\
\hline & Expert IV & 0.10 & $75 \%$ & \\
\hline \multirow{4}{*}{$\begin{array}{c}\text { Proposed } \\
\text { Model }\end{array}$} & Expert I & 0.50 & $95 \%$ & \multirow{4}{*}{$91 \%$} \\
\hline & Expert II & 0.20 & $90 \%$ & \\
\hline & Expert III & 0.20 & $80 \%$ & \\
\hline & Expert IV & 0.10 & $90 \%$ & \\
\hline
\end{tabular}

Where:

Weights column refers to normalized experience weights (w), Primary column refers to expert's confidence (i.e. satisfaction level (p)), and

Final column refers to group confidence level (f).

$$
\mathrm{f}=\sum_{\mathrm{i}=1}^{4} \mathrm{w}_{\mathrm{i}} \mathrm{p}_{\mathrm{i}}
$$


By multiplying the evaluated values, taken from each expert to the results, by his suggested weight, and summed these multiplied values, a voting can be taken for each method. It is clear that the proposed model is the closest to the optimum among all the proposed methodologies.

\section{CONCLUSIONS}

In the proposed model it is possible to gain the advantages of both interval and fixed value judgments. Insufficiency of each of them can be avoided. GFANP model provides expert judgments the ability of using interval values in their preference matrices instead of crisp values. As Gaussian fuzzy numbers are used instead of triangular numbers the case of zero weights will never exist. The proposed model gives better results than both ANP and triangular fuzzy ANP methods.

\section{REFERENCES}

[1] Chan, F. T. S. and Kumar, N. 2007. Global Supplier Development Considering Risk Factors Using Fuzzy Extended AHP-Based Approach. Omega. Vol. 35. No. 4 (Aug. 2007), 417-431.

[2] Chen, M. Y., and Linkens, D. A. 2001. A Systematic Neuro-Fuzzy Modeling Framework With Application to Material Property Prediction. IEEE Transactions Systems Manufacturing, Cybernetics. Part B. Vol. 31, No. 5. (Oct. 2001), 781-790.

[3] Wu, S., Er, M. J., and Gao, Y. 2001. A Fast Approach for Automatic Generation of Fuzzy Rules by Generalized Dynamic Fuzzy Neural Networks. IEEE Transactions on Fuzzy Systems. Vol. 9. No. 4 (Aug. 2001), 578-594.

[4] "Electricity Generation", last visit on October 2013, available http://en.wikipedia.org/wiki/Electricity_generation

[5] Zhang, R., Zhou, J., and Wang, Y. 2012. Multi-objective optimization of hydrothermal energy system considering economic and environmental aspects. International Journal of Electrical Power \& Energy Systems. Vol. 42. Issue 1 (Nov. 2012), 384-395.

[6] Sahu, S. K., Bhangare, R. C., Ajmal, P. Y., Sharma, S.,Pandit, G. G., and Puranik, V. D. 2009. Characterization and quantification of persistent organic pollutants in fly ashnfrom coal fueled thermal power stations in India. Microchemical Journal. Vol. 92. No. 1 (May 2009), 92-96.

[7] Ha, D. W., Kwon, J. M., Baik, S. K., Lee, Y. J., Han, K. S., Ko, R. K., Sohn, M. H., and Seong, K. C. 2011. Purification of condenser water in thermal power station by Superconducting magnetic separation. Physica C: Superconductivity. Vol. 471. Issues 21-22 (Nov. 2011), 1530-1532.

[8] Jiang, Z., Zeng, J., Chen, Q., Huang, Y., Xu, X., Liao, Y., Shou, L., and Liu, J. 2008. Tolerance of copepods to short-term thermal stress caused by coastal power stations. Journal of Thermal Biology. Vol. 33, No. 7 (Oct. 2008), 419-423.

[9] Smoot, L. D. and Baxter, L. L. 2003. Fossil Fuel Power Stations - Coal Utilization. Encyclopedia of Physical Science and Technology (Third Edition), 121-144.

[10] Popov, D. 2011. An option for solar thermal repowering of fossil fuel fired power plants. Solar Energy. Vol. 85. No. 2 (Feb. 2011), 344-349.
[11] Visschers, V. H. M., Keller, C., and Siegrist, M. 2011. Climate change benefits and energy supply benefits as determinants of acceptance of nuclear power stations: Investigating an explanatory model. Energy Policy. Vol. 39. No. 6 (June 2011), 3621-3629.

[12] Gao, H., Jiao, X., Zhou, C., Shen, Q., and Yu, Y. 2011. Study on Remote Control Underwater Welding Technology Applied in Nuclear Power Station. Procedia Engineering. Vol. 15, 4988-4993.

[13] "Hydroelectricity", last visit on October 2013, available at: http://en.wikipedia.org/wiki/Hydroelectricity

[14] Sovacool, B. K., Dhakal, S., Gippner, O., and Bambawale, M. J. 2011. Halting hydro: A review of the socio-technical barriers to hydroelectric power plants in Nepal. Energy. Vol. 36. No. 5 (May 2011), 3468-3476.

[15] "Wind Power", last visit on October 2013, available at: http://en.wikipedia.org/wiki/Wind_power

[16] [16] "Solar Energy", last visit on October 2013, available at: http://en.wikipedia.org/wiki/Solar_energy

[17] [17] Xu, S. M., Huang, X. D., and Du, R. 2011 An investigation of the solar powered absorption refrigeration system with advanced energy storage technology. Solar Energy, Vol. 85. No. 9 (Seb. 2011), 1794-1804.

[18] "Electrical Power in Egypt", last visit on October 2013, available http://www.mbendi.com/indy/powr/af/eg/p0005.htm

[19] [19] Yuksel, I. and Dagdeviren, M. 2007. Using The Analytic Network Process (ANP) in a SWOT Analysis A Case Study For a Textile Firm. Information Sciences. Vol. 177 (Aug. 2007), 3364-3382.

[20] Ravia, V., Shankara, R., and Tiwarib, M. K. 2005. Analyzing alternatives in reverse logistics for end-of-life computers: ANP and balanced scorecard approach. Computers \& Industrial Engineering. Vol. 48 (Mar. 2005), $327-356$

[21] Liu, H. and Wang, C. 2010. An advanced quality function deployment model using fuzzy analytic network process. Applied Mathematical Modeling. Vol. 34 (Nov. 2010), 3333-3351.

[22] Luo, Z., Zhou, J., Zheng, L., Mo, L., and He, Y. 2010. A TFN-ANP based approach to evaluate Virtual Research Center comprehensive performance. Expert Systems with Applications. Vol. 37 (Dec. 2010), 8379-8386.

[23] Sevkli , M., Oztekin, A., Uysal, O., Torlak, G., Turkyilmaz, A., and Delen, D. 2012. Development of a fuzzy ANP based SWOT analysis for the airline industry in Turkey. Expert Systems with Applications. Vol. 39 (Jan. 2010), 14-24.

[24] Hsu, T., Hung, L., and Tang, J. 2012. A Hybrid ANP Evaluation Model for Electronic Service Quality. Applied Soft Computing. Vol. 12 (Jan. 2012), 72-81.

[25] Hefny, H. A. 2007. Comments on "Distinguishability Quantification of Fuzzy Sets". Information Sciences. Vol. 177 (Nov. 2007), 4832-4839. 